\title{
Inducible Clindamycin Resistance among Clinical Isolates of Staphylococcus aureus in a Tertiary Care Hospital, Nanded, Maharashtra, India
}

\author{
Sanjay Kumar R. More ${ }^{1 *}$, Kasturi ${ }^{2}$, Vimal S. Rathod ${ }^{2}$, Rohit Sinha ${ }^{2}$ and Saleha Khan ${ }^{2}$ \\ ${ }^{1}$ Department of Microbiology, Swami Ramanand Teerth Rural Govt. Medical College, \\ Ambajogai, Maharashtra, India \\ ${ }^{2}$ Department of Microbiology, Dr. S C Govt. Medical College, Nanded, Maharashtra, India \\ *Corresponding author
}

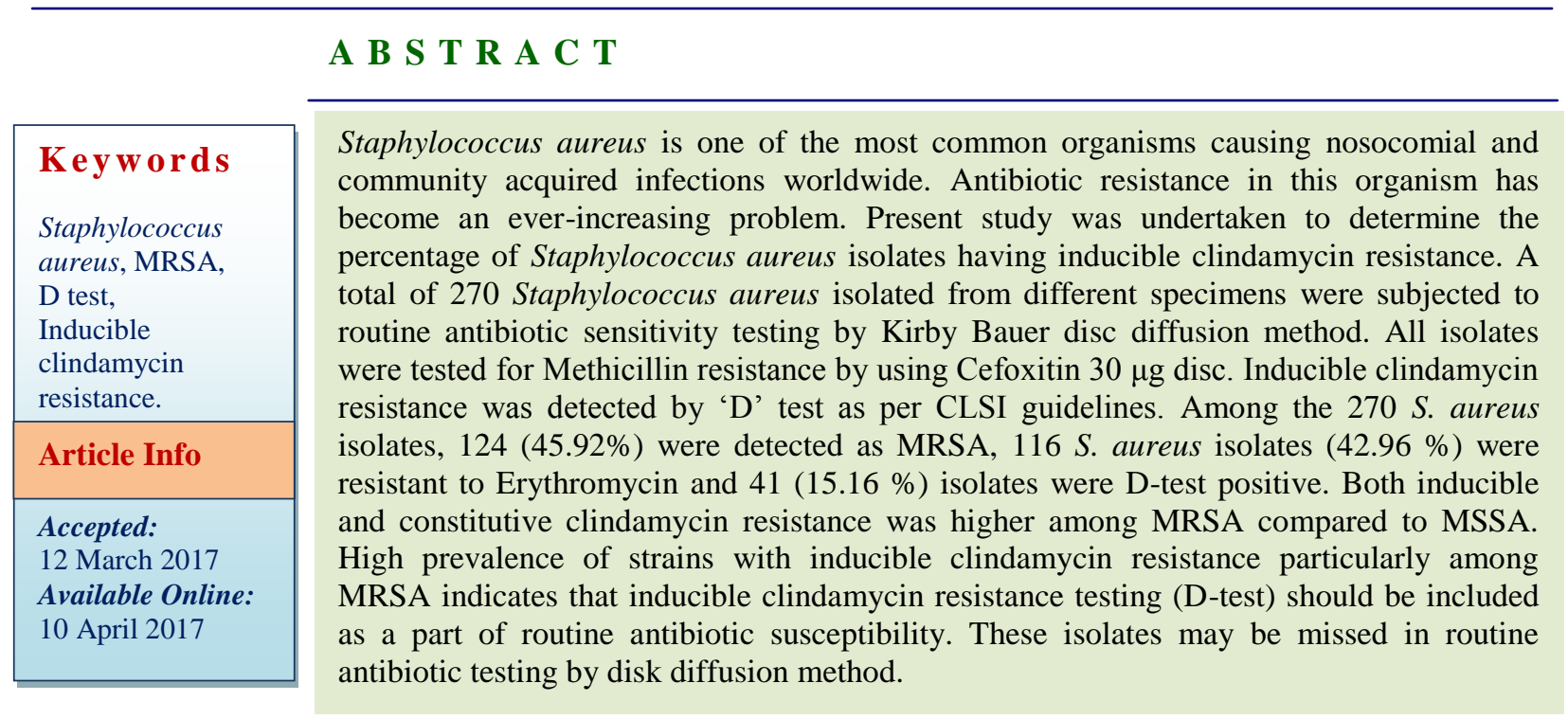

\section{Introduction}

Staphylococcus aureus is one of the most common organisms causing nosocomial and community acquired infections worldwide (Prabhu et al., 2011). These bacteria can cause a wide range of infections from mild folliculitis to potentially fatal systemic illnesses such as bacteremia or endocarditis (Seifi et al., 2012). Antibiotic resistance in this organism has become an ever-increasing problem. In Staphylococcus aureus, penicillin resistance was recognized first in 1944 and methicillin resistance was recognized first in 1961(Gade et al., 2013). This has led to the usage of macrolide - lincosamide streptogramin $\mathrm{B}\left(\mathrm{MLS}_{\mathrm{B}}\right)$ antibiotics to treat
S. aureus infections, with Clindamycin being the preferable agent due to its excellent pharmacokinetic properties (Kaur et al., 2013). However, widespread use of $M L S_{B}$ antibiotics has led to an increase in the number of staphylococcal strains acquiring resistance to $\mathrm{MLS}_{\mathrm{B}}$ antibiotics (Dhanalakshmi et al., 2012).

Macrolide and lincosamide resistance is mainly due to one of these three mechanisms (Leclercq, 2002).

a) Target site modification: Ribosomal methylation or mutation which prevents 
binding of antibiotic to its ribosomal target. This is the most prevalent mechanism of resistance to macrolides and lincosamides encoded by erm genes.

b) Efflux of antibiotic: encoded by $m s r A$ gene

c) Drug inactivation: encoded by $\ln u$ genes

Modification of ribosomal target which confers broad-spectrum resistance to macrolides and lincosamides is encoded by a variety of erm (erythromycin ribosome methylase) genes. ErmA and ermC are typically Staphylococcal genes. This mechanism can be constitutive (cMLS); always producing the rRNA methylase, or inducible (iMLS), that is producing methylase only in the presence of an inducer (Saderi et al., 2009). In vitro, S. aureus isolates with constitutive resistance are resistant to both Erythromycin and Clindamycin whereas those with inducible resistance are resistant to Erythromycin and appear sensitive to Clindamycin $\left(\mathrm{iMLS}_{\mathrm{B}}\right)$ (Lyall et al., 2013). The treatment of patients harboringi $\mathrm{MLS}_{\mathrm{B}}$ Staphylococci with Clindamycin leads to the development of constitutive resistance, subsequently leading to therapeutic failure.

Frequencies of different resistance phenotypes vary by hospital and geographical regions, patient group, bacterial strains and bacterial susceptibility pattern (Zorgani et al., 2009). Thus, the present study was undertaken to determine the percentage of Staphylococcus aureus isolates having inducible clindamycin resistance in our geographical area.

\section{Materials and Methods}

This study was conducted for the period of 1 year and 6 months, from July 2015 to December 2016 in the Department of Microbiology, Dr. Shankarrao Chavan Government Medical College, Nanded. A total of 270 isolates of S. aureus isolated from clinical specimens such as pus, wound swab, blood, urine, cerebrospinal fluid, sputum and other body fluids were considered for the study.

Isolates were identified on the basis of colony characteristics, Gram staining, catalase test, slide coagulase test, tube coagulase test, growth on mannitol salt agar and DNase test (Collee, 2012). Antibiotic susceptibility tests were performed using Kirby Bauer's disc diffusion method according to Clinical and Laboratory Standards Institute (CLSI) guidelines 2014.

Drugs used were Erythromycin $(15 \mu \mathrm{g})$, Clindamycin $(2 \mu \mathrm{g})$, Penicillin (10 Units), Linezolid $(30 \mu \mathrm{g}), \quad$ Cefoxitin $(30 \mu \mathrm{g})$, Cotrimoxazole $(1.25 / 23.75 \mu \mathrm{g})$, Ciprofloxacin $(5 \mu \mathrm{g})$, Vancomycin $(30 \mu \mathrm{g})$. MRSA were screened using Cefoxitin $(30 \mu \mathrm{g})$ disc by discdiffusion technique (M 100-S 25.CLSI, 2014). The results were interpreted according to CLSI guidelines. Staphylococcus aureus ATCC 25923 was taken as the positive control strain.

Isolates that were Clindamycin susceptible and Erythromycin resistant were tested for inducible resistance by the use of D-zone test.

D-zone test: A 0.5 McFarland equivalent suspension of organisms was incubated on Muller-Hinton agar (MHA) plate as described in the CLSI recommendations. Clindamycin and Erythromycin disks were placed 15$26 \mathrm{~mm}$ apart from each other on the MHA plates. After 18hours incubation at $37^{\circ} \mathrm{C}$, plates were checked. Flattening of inhibition zone (D-shaped) around clindamycin was considered as inducible clindamycin resistance.

The test allows for identification of three different phenotypes: 
a) Inducible $\mathrm{MLS}_{\mathrm{B}}$ phenotype: iMLSB $S$. aureus isolates which showed resistance to Erythromycin (zone size $\leq 13 \mathrm{~mm}$ ) while being sensitive to Clindamycin (zone size $\geq 21 \mathrm{~mm}$ ) and giving $\mathrm{D}$ shaped zone of inhibition around Clindamycin with flattening towards Erythromycin disc (D test positive)

b) Constitutive $\mathrm{MLS}_{\mathrm{B}}$ phenotype: $\mathrm{cMLS}_{\mathrm{B}} S$. aureus isolates which showed resistance to both Erythromycin (zone size $\leq 13 \mathrm{~mm}$ ) and Clindamycin (zone size $\leq 14 \mathrm{~mm}$ ) with circular shape zone of inhibition around Clindamycin.

c) Methicillin-sensitive (MS) phenotype: $S$. aureus isolates exhibiting resistance to Erythromycin (zone size $\leq 13 \mathrm{~mm}$ ), while sensitive to Clindamycin (zone size $\geq 21$ $\mathrm{mm}$ ) and giving circular zone of inhibition around Clindamycin (D test negative).

\section{Results and Discussion}

A total of $270 \mathrm{~S}$. aureus isolates were obtained from specimens such as pus and wound swabs, blood, urine, sputum, aspirates, and body fluids. Majority of these were detected from pus and wound swabs (54.07\%), followed by urine (19.6\%), blood (9.63\%), body fluids / aspirates $(9.26 \%)$ and sputum (7.41\%). Most of these specimens were from inpatients $(62.22 \%)$ (Table 1$)$.

Out of $270 \mathrm{~S}$. aureus isolates, $146(54.07 \%)$ were Methicillin-sensitive Staphylococcus aureus (MSSA), and 124 (45.92\%) were Methicillin-resistant Staphylococcus aureus (MRSA) (Figure 1).

All 270 isolates were subjected to antimicrobial susceptibility testing. These showed $100 \%$ sensitivity to vancomycin and linezolid, $116 \mathrm{~S}$. aureus isolates (42.96\%) were resistant to Erythromycin, out of which
$57.26 \%$ (71) were MRSA and 30.82\% (45) were MSSA (Table 2 and Figure 2).

The result of the $\mathrm{D}^{-}$test revealed that 42(11 MSSA, 31 MRSA) isolates were resistant to both Erythromycin and Clindamycin indicating $\mathrm{cMLS}_{\mathrm{B}}$ phenotype. 33 (21 MSSA, 12 MRSA) isolates were $D^{-}$test negative, indicating MS phenotype. These isolates were truly susceptible to Clindamycin and 41 (13 MSSA, 28 MRSA) isolates were D- test positive, indicating $\mathrm{iMLS}_{\mathrm{B}}$ phenotype. These isolates were actually resistant to Clindamycin which would have been easily missed and reported as Clindamycin susceptible in regular Kirby-Bauerdisk diffusion susceptibility testing. The study also showed that higher percentage MRSA isolates were both constitutive and inducible clindamycin resistant in comparison to MSSA (Table 3 and Figure 3).

Clindamycin, a lincosamide, is one of the most efficient antibiotics in treating staphylococcal skin and soft tissue infections. It is available in oral and parenteral formulations, $90 \%$ oral bioavailability, less costly in comparison to newer drugs, good tissue penetration and is able to inhibit production of toxins and virulence factors in Staphylococci (Majhi et al., 2016).

However, resistance to Clindamycin is highly variable, and incidence of its resistant phenotypes varies by geographic regions and even between hospitals (Fiebelkorn et al., 2003). These isolates have a high rate of spontaneous mutation during the therapeutic process which would enable them to develop resistance to Clindamycin (Prabhu et al., 2011). Thus, the empirical treatment options against $S$. aureus infections have become more limited.

Therefore, this study was undertaken to detect and report the presence of Clindamycin- 
resistant phenotypes in a tertiary care hospital.

In this study, majority (54.07\%) of the $S$. aureus isolates was detected from pus and wound swabs. It is in accordance to other studies done by Lyall et al., (2013) and Majhi et al., (2016). Most of the isolates (62.22\%) were obtained from hospitalized patients as also observed by Majhi et al., (2016).

Prevalence of MRSA in our study is $45.92 \%$ which resembles with the reports of Gade et al., (2013). The prevalence of MRSA isolates among $S$. aureus was high in studies done by Lyall et al., (2013), Majhi et al., (2016) and Sah et al., (2015). Lack of awareness, indiscriminate and improper use of antibiotics before coming to the hospital might be the contributory factors for a high prevalence of MRSA. In our study, none of the isolates were resistant to Vancomycin or Linezolid and $42.96 \%$ of $S$. aureus isolates were resistant to Erythromycin. Similar high prevalence of resistance to Erythromycin has reported by Mittal et al., (2013) and Sasirekha et al., (2014).

Our study revealed $41(15.16 \%)$ S. aureus isolates were D- test positive. It was observed that percentage of inducible clindamycin resistance was higher among MRSA (22.58\%) compared to MSSA (8.9\%).This finding conforms to many published studies such as Gade et al., (2013), Majhi et al., (2016) and Lall et al., (2014). On the contrary, Sasirekha et al., (2014) and Bottega et al., (2014) had shown a higher percentage of inducible resistance in MSSA compared to MRSA.

Table.1 Distribution of specimens

\begin{tabular}{|l|l|l|l|}
\hline \multicolumn{1}{|c|}{ Specimen } & \multicolumn{1}{c|}{$\begin{array}{c}\text { OPD } \\
\text { No. }(\%)\end{array}$} & $\begin{array}{c}\text { IPD } \\
\text { No. }(\%)\end{array}$ & $\begin{array}{c}\text { Total } \\
\text { No. }(\%)\end{array}$ \\
\hline Wound swab/pus & $55(20.37 \%)$ & $91(33.70 \%)$ & $146(54.07 \%)$ \\
\hline Urine & $23(8.52 \%)$ & $30(11.11 \%)$ & $53(19.63 \%)$ \\
\hline Blood & $05(1.85 \%)$ & $21(7.77 \%)$ & $26(9.63 \%)$ \\
\hline Sputum & $09(3.33 \%)$ & $11(4.07 \%)$ & $20(7.41 \%)$ \\
\hline Body fluids/aspirates & $10(3.70 \%)$ & $15(5.55 \%)$ & $25(9.26 \%)$ \\
\hline Total & $102(37.78 \%)$ & $168(62.22 \%)$ & $270(100 \%)$ \\
\hline
\end{tabular}

Table.2 Antibiotic resistance pattern among MSSA and MRSA isolates

\begin{tabular}{|l|l|l|}
\hline Antibiotics & MSSA (146) & MRSA (124) \\
\hline Vancomycin $(30 \mu \mathrm{g})$ & 00 & 00 \\
\hline Linezolid $(30 \mu \mathrm{g})$ & 00 & 00 \\
\hline Cefoxitin $(30 \mu \mathrm{g})$ & 00 & $100 \%(124)$ \\
\hline Clindamycin $(2 \mu \mathrm{g})$ & $16.44 \%(24)$ & $47.58 \%(59)$ \\
\hline Erythromycin $(15 \mu \mathrm{g})$ & $30.82 \%(45)$ & $57.26 \%(71)$ \\
\hline Cotrimoxazole $(1.25 / 23.75 \mu \mathrm{g})$ & $40.41 \%(59)$ & $58.06 \%(72)$ \\
\hline Ciprofloxacin $(5 \mu \mathrm{g})$ & $32.19 \%(47)$ & $59.68 \%(74)$ \\
\hline Penicillin $(10$ Units) & $81.51 \%(119)$ & $88.71 \%(110)$ \\
\hline
\end{tabular}


Table.3 Results of D-Zone test

\begin{tabular}{|l|c|c|c|}
\hline & MS phenotype (\%) & $\begin{array}{c}\text { Inducible } \text { MLS }_{\mathrm{B}} \\
\text { phenotype }(\%)\end{array}$ & $\begin{array}{c}\text { Constitutive } \text { MLS }_{\mathrm{B}} \\
\text { phenotype }(\%)\end{array}$ \\
\hline MRSA (n=124) & $12(9.68 \%)$ & $28(22.58 \%)$ & $31(25 \%)$ \\
\hline MSSA (n=146) & $21(14.38 \%)$ & $13(8.9 \%)$ & $11(7.5 \%)$ \\
\hline Total (n=270) & $33(12.22 \%)$ & $41(15.16 \%)$ & $42(15.56 \%)$ \\
\hline
\end{tabular}

Fig.1 Prevalence of MRSA

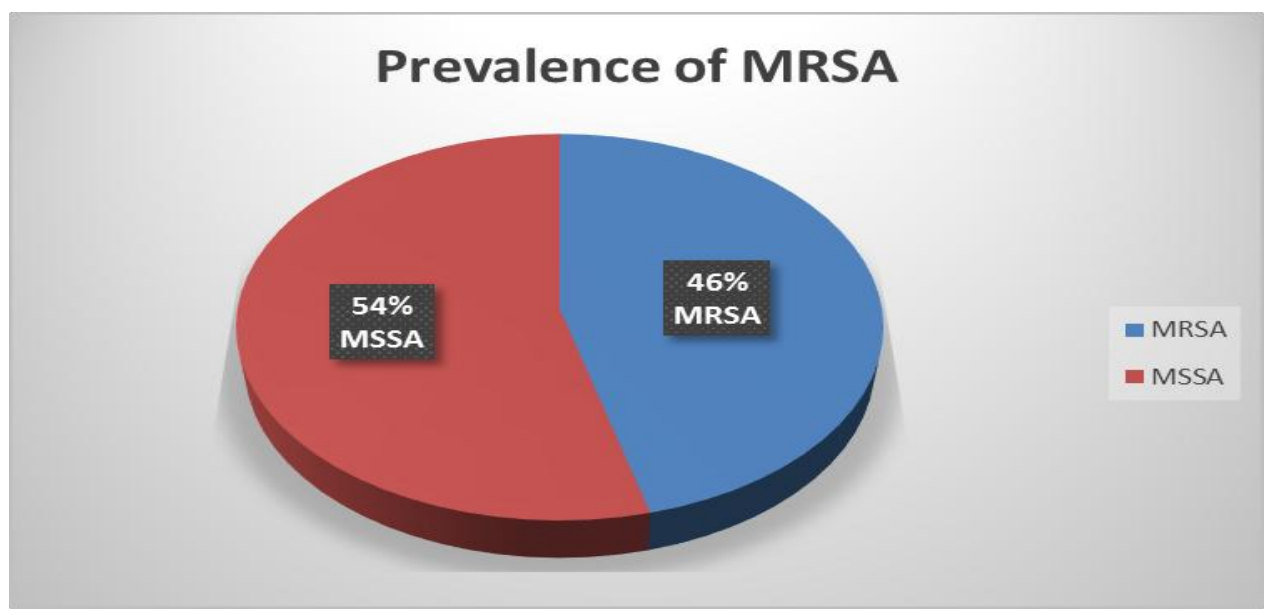

Fig.2 Antibiotic resistance pattern among MSSA and MRSA isolates

ANTIBIOTIC RESISTANCE PATTERN AMONG MSSA AND MRSA ISOLATES

MSSA MRSA
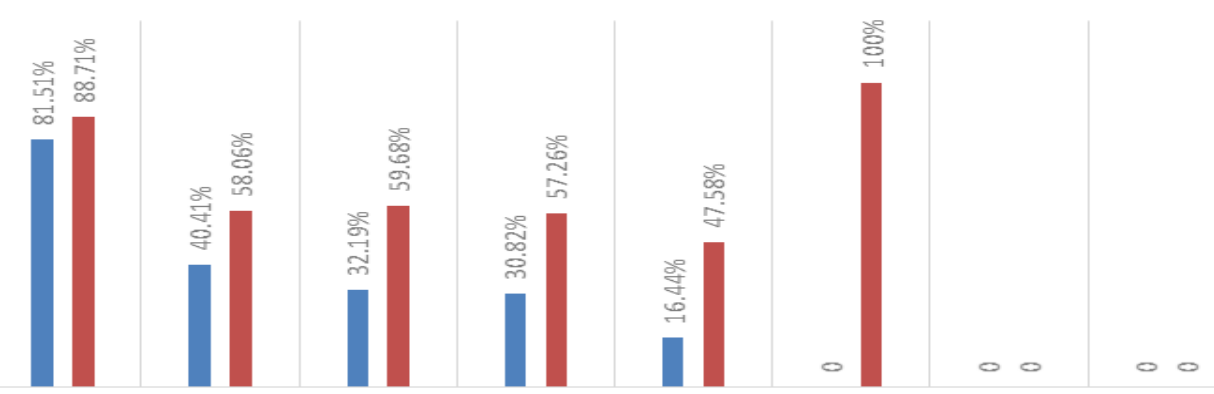
Fig.3 Results of D-Zone test

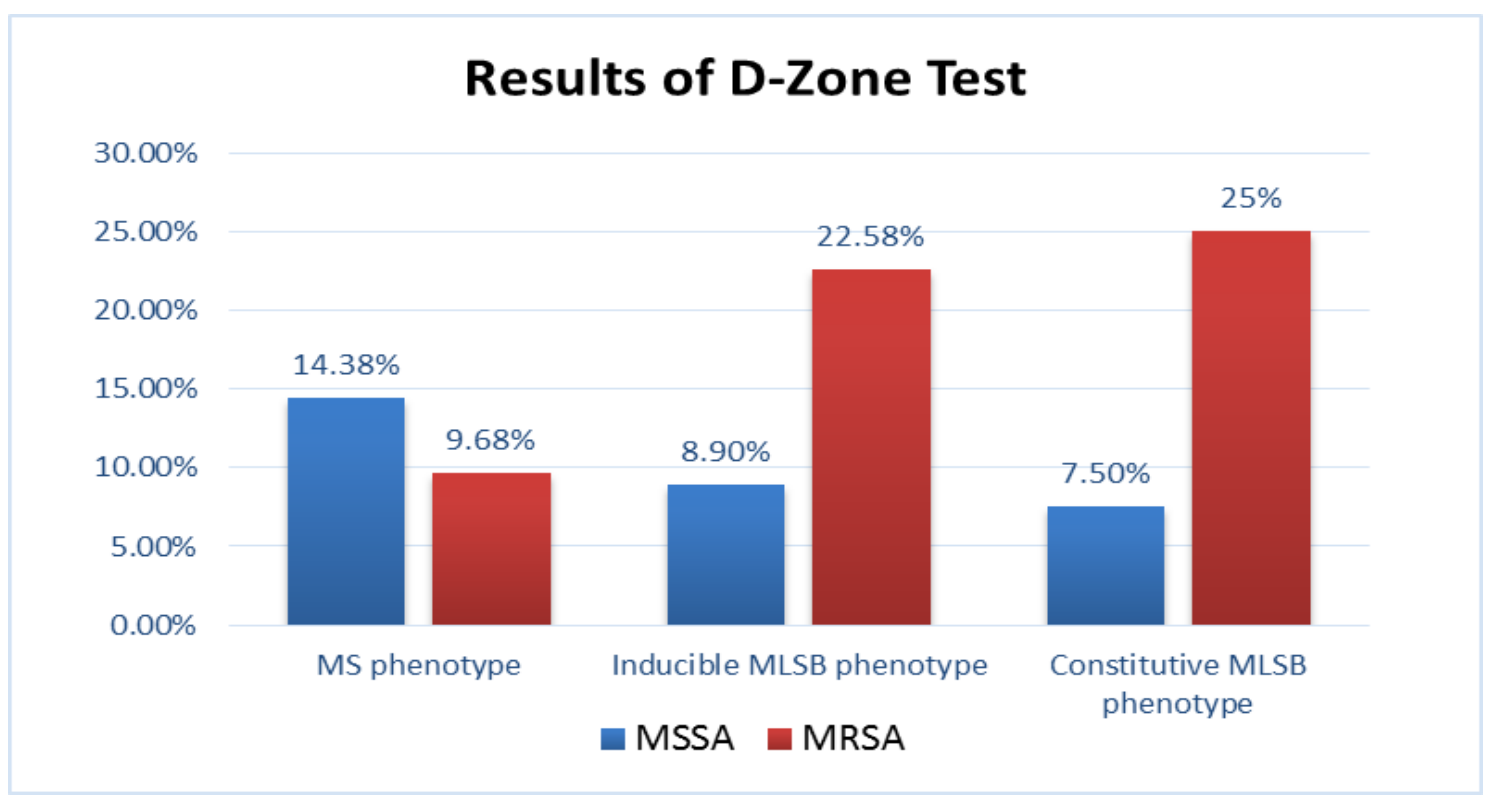

The different patterns of resistance observed in various studies are due to the fact that resistance varies by geographical regions, age groups, antibiotic prescription patterns, methicillin susceptibility and even from hospital to hospital.

Constitutive clindamycin resistance in our study was observed in $7.5 \%$ of MSSA and $25 \%$ of MRSA isolates, which is similar to Majhi et al., (2016) and Chudasama et al., (2014). Truly clindamycin- sensitive isolates, which exhibit MS phenotype, were present in $14.38 \%$ of MSSA and $9.68 \%$ of MRSA isolates in our study. This result is similar to Banik et al., (2015) and Phukan et al., (2015).

In conclusion, from the current study, we can conclude that there is a high percentage of inducible clindamycin resistance amongst the staphylococcal isolates. If $\mathrm{D}^{-}$test would not have been performed, many inducible clindamycin resistant $S$. aureus could have been easily misidentified as clindamycin susceptible leading to therapeutic failure.
Thus, simple and reliable $\mathrm{D}^{-}$test can be incorporated into routine Kirby-Bauer disk diffusion method in clinical microbiology laboratory. This will enable us in guiding the clinicians regarding judicious use of Clindamycin in skin and soft tissue infections as Clindamycin is not a suitable drug for $\mathrm{D}$ test positive isolates; while it can definitely prove to be a drug of choice in case of $\mathrm{D}$ test negative isolates.

\section{Acknowledgement}

The Authors are thankful to the Dean, Dr. Shankarrao Chavan Government Medical College, Nanded for providing the necessary facilities and permitting to carry out this research work.

\section{References}

Banik, A., Khyriem, A.B., Gurung, J., Lyngdoh, V.W. 2015. Inducible and constitutive clindamycin resistance in Staphylococcus aureus in a Northeastern Indian tertiary care hospital. J. Infect. Dev. Ctries., 9: 72531. 
Bottega, A., Rodrigues Mde, A., Carvalho, F.A., Wagner, T.F., Leal, I.A., Santos, S.O. 2014. Evaluation of constitutive and inducible resistance to clindamycin in clinical samples of Staphylococcus aureus from a tertiary hospital. Rev. Soc. Bras. Med. Trop., 47: 589-92.

Chudasama, V., Solanki, H., Vadsmiya, M., Vegad, M.M. 2014. Prevalence of inducible clindamycin resistance of Staphylococcus aureus from various clinical specimens by D test in tertiary care hospital. IOSR J. Dent. Med. Sci., 13: 29-32.

Collee, J.G., Fraser, A.G., Marmion, B.P., Simmons, A. 2012. Mackie and McCartney Practical Medical Microbiology, 14th edition, Elsevier publication.

Dhanalakshmi, T.A., Umapathy, B.L., Mohan, D.R. 2012. Prevalence of inducible clindamycin resistance in Staphylococcus aureus. J. Acad. Med. Sci., 2: 73-5.

Fiebelkorn, K.R., Crawford, S.A., McElmeel, M.L., Jorgensen, J.H. Practical disk diffusion method for detection of inducible clindamycin resistance in Staphylococcus aureus and coagulasenegative staphylococci. J. Clin. Microbiol., 41: 4740-4.

Gade, N.D., Qazi, M.S. 2013. Inducible clindamycin resistance among Staphylococcus aureus isolates. Indian J. Basic Appl. Med. Res., 2(8): 961-967.

Kaur, D.C., Khare, A.S. 2013. Inducible clindamycin resistance in Staphylococcus aureus in a tertiary care rural hospital. Indian J. Basic Appl. Med. Res., 2: 686-93.

Lall, M., Sahni, A.K. 2014. Prevalence of inducible clindamycin resistance in Staphylococcus aureus isolated from clinical samples. Med. J. Armed Forces India, 70: 43-7.

Leclercq, R. 2002. Mechanism of resistance to macrolides and lincosamides: naure of resistance elements and their clinical implications. Clin. Infect. Dis., 34: 48292.

Lyall, K.S., Gupta, V., Chhina, D. 2013. Inducible clindamycin resistance among clinical isolates of Staphylococcus aureus. J. Mahatma Gandhi Inst. Med. Sci., 18: 112-5.

M 100-S 25. Performance standards for antimicrobial susceptibility testing 24th informational supplement CLSI; Clinical Laboratory Standards Institute January 2014.

Majhi, S., Dash, M., Mohapatra, D., Mohapatra, A., Chayani, N. 2016. Detection of inducible and constitutive clindamycin resistance among Staphylococcus aureus isolates in a tertiary care hospital, Eastern India. Avicenna J. Med., 6: 75-80.

Mittal, V., Kishore, S., Siddique, M.E. 2013. Prevalence of inducible clindamycin resistance among clinical aureus isolates of staphylococcus detected by phenotypic method: A Preliminary report. J. Infect. Dis. Immunity, 5: 10-2.

Phukan, C., Ahmed, G.U., Sarma, P.P. 2015. Inducible clindamycin resistance among Staphylococcus aureus isolates in a tertiary care hospital of Assam. Indian J. Med. Microbiol., 33: 456-8.

Prabhu, K., Rao, S., Rao, V. 2011. Inducible clindamycin resistance in Staphylococcus aureus isolated from clinical samples. J. Lab. Physicians, 3: 25-7.

Saderi, H., Owlia, P., Eslami, M. 2009. Prevalence of Macrolide-LincosamideStreptogamin B (MLS) resistance in $S$. aureus isolated from patients in Tehran, Iran. Iran J. Pathol., 4: 161-166.

Sah, P., Khanal, R., Lamichhane, P., Upadhaya, S., Lamsal, A., Pahwa, V.K. 2015. Inducible and constitutive clindamycin resistance in 
Staphylococcus aureus: An experience from Western Nepal. Int. J. Biomed. Res., 6: 316-9.

Sasirekha, B., Usha, M.S., Amruta, J.A., Ankit, S., Brinda, N., Divya, R. Incidence of constitutive and inducible clindamycin resistance among hospitalassociated Staphylococcus aureus. Biotech., 4: 85-9.

Seifi, N., Kahani, N., Askari, E., Mahdipour,
S., Naderi, N.M. 2012. Inducible clindamycin resistance in Staphylococcus aureus isolates recovered from Mashhad, Iran. Iran J. Microbiol., 4(2): 82-86.

Zorgani, A., Shawerf, O., Tawil, K., ElTurkey, E., Gheghesh, K.S. 2009. Inducible clindamycin resistance among staphylococci isolated from burn patients. Libyan J. Med., 4: 104-106.

\section{How to cite this article:}

Sanjay Kumar R. More, Kasturi, Vimal S. Rathod, Rohit Sinha, Saleha Khan. 2017. Inducible Clindamycin Resistance among Clinical Isolates of Staphylococcus aureus in a Tertiary Care Hospital, Nanded, Maharashtra. Int.J.Curr.Microbiol.App.Sci. 6(4): 1232-1239. doi: https://doi.org/10.20546/ijcmas.2017.604.151 